sites on which the stand occurs. On these plots, all the sporophore-bearing trees of merchantable size were analysed. These totalled fifty-nine, of which thirtytwo, or 54.2 per cent, contained one or more sound, merchantable logs. This is practically the same ratio as was found on the plot represented in Table 1.

From the facts here presented, it is evident that, within the scope of this investigation, the mere presence of sporophores of $F$. igniarius does not indicate a cull tree. It has been shown that a substantial proportion, (in this case, more than half) of the merchantable sized, sporophore-bearing trecs, contain sound logs, and the decay-containing portion is usually but a few feet longer than the sporophore-bearing part. Sporophores may, however, be used with a considerable degree of accuracy, in estimating the proportion of cull in standing trees. A little time spent on investigating the condition of a few trees, will furnish a basis for interpretation of these signs, so that little time need subsequently be lost through cutting into worthless wood, and little sound wood need be left. Log makers can quickly become adept at estimating the point where decay ends and sound wood begins. The study is not sufficiently advanced to permit of a general statement of rules to be followed for this purpose, and it is questionable if such rules would have much practical value. In the end, it is only by familiarity with local conditions that the maximum product may be realized from any stand.

\title{
SHERWOOD FOREST CAMP
}

7 HIS enterprise of one of our members is worthy of mention and will, I am sure be of interest to our members in general. It is a camp for boys where they ran pass the summer under the care of a trained for-

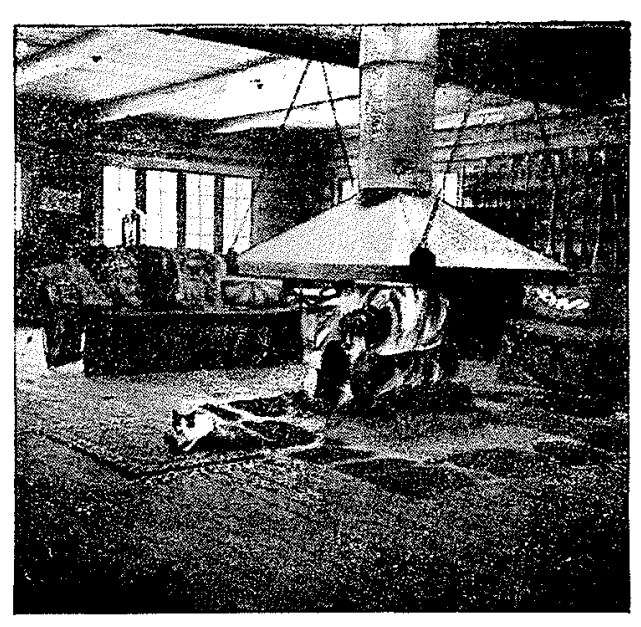
ester and imbibe a love for the woods, not only from the standpoint of beauty but also that of utility and their place in the economic structure of the country. It is situated on Big Boshkung Lake, 12 miles north of Minden in Haliburton County, Ont. 135 miles from Toronto. During the fall the camp is open to adults.

A feature of the camp which may be of special interest to foresters, especially those who operate and have depots 
and company camps to heat, is the modification of the old-fashioned open fire caboose shown in our illustrations. In the middle of the floor a cement pier, dry stone may replace this, with an airshaft down through the center, is built flush with the floor and finished off with a border of flat stones. An iron grate covers the air shaft, and a damper is inserted below to control the draft. Sus-pended and counter weighted over this a steel canopy 40 " $\times 60^{\prime \prime}$ with a fifteen inch flue of telescoping pipe, so that it may be raised or lowered at will. A box 30" high and just big enough to fit inside the canopy can be moved into place at night and transforms the fire place into a large box stove which will heat the camp to any degree desired. This box could be attached to or made a part of the canopy and raised or lowered with it. When the fireplace is used as a stove the box has a large door in each end for feeding in the wood. It will take a quarter of a cord at a time. When filled with inferior or green wood and the drafts closed it will keep the building warm all night, and when started up in the morning will heat the building in a jiffy.

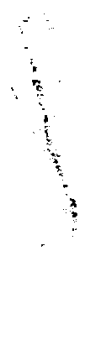

